\title{
Salvator Mundi: an investigation of the painting's materials and techniques
}

\author{
Nica Gutman Rieppi ${ }^{1 *}$, Beth A. Price ${ }^{2}$, Ken Sutherland ${ }^{2,3}$, Andrew P. Lins ${ }^{2}$, Richard Newman ${ }^{4}$, Peng Wang ${ }^{5}$, \\ Ting Wang ${ }^{5}$ and Thomas J. Tague $\mathrm{Jr}^{5}$
}

\begin{abstract}
Before the start of its restoration in 2007, the Salvator Mundi was thought to be one of a number of copies of a longlost Leonardo da Vinci painting, depicting Christ giving a blessing with his right hand while holding a crystal orb in his left. During the restoration treatment, a scientific examination of the painting was carried out to elucidate the painting's materials and techniques. Microscopic sampling of the painting was necessarily limited, and nine out of ten samples were prepared and analyzed as cross-sections. A number of analytical methods were employed selectively, including stereomicroscopy, visible and fluorescent light microscopy, scanning electron microscopy with energy dispersive spectroscopy, Raman microspectroscopy, Fourier transform infrared microspectroscopy in transmission mode and with attenuated total reflection. The pigments characterized were lead white, vermilion, red iron oxide earth, red lake, natural ultramarine, lead-tin yellow, umber, and charcoal, carbon and bone blacks. Manganese-containing soda-lime glass was detected in the ground, imprimitura and paint layers, and a walnut oil medium was identified by pyrolysis gas chromatography-mass spectrometry. Cross-section studies revealed aspects of the painting's stratigraphy: a size layer, white ground and off-white imprimitura, followed by a complex sequence of paint layers applied by the artist to achieve sophisticated visual effects.
\end{abstract}

Keywords: Salvator Mundi, Panel painting, Cross-section, Raman, SEM, FTIR, Py-GCMS, Pigments

\section{Introduction}

In 2017, the painting Salvator Mundi was sold as a rediscovered work by Leonardo da Vinci by Christie's auction house (Fig. 1). However, prior to its restoration treatment between 2007 and 2011, the painting was thought to be one of a number of copies of the possible, long-lost Leonardo painting, an image of which was depicted in a 1650 etching by Wenceslaus Hollar bearing the Latin inscription "Leonardus da Vinci pinxit" ("Leonardo painted it") [1]. After the layers of discolored varnish and overpaint were removed, the paint handling and surface details of the painting were revealed, leading to a reassessment of its authorship by Leonardo scholars [1, 2]. The uncovering of the original paint surface, affected by paint loss and

\footnotetext{
*Correspondence: nrieppi@gmail.com

1 Art Analysis \& Research, LLC, New York, NY 10018, USA

Full list of author information is available at the end of the article
}

abrasion, provided a unique opportunity for examination of the painting's materials and techniques. ${ }^{1}$ Certain aspects of the technical examination, including infrared reflectography and X-radiography, have been discussed in a separate publication, which also gives a detailed account of the restoration treatment [2]. In addition to these forms of examination, during the early stages of the restoration, microscopic samples were obtained from inconspicuous yet relatively intact areas of paint and

\footnotetext{
${ }^{1}$ Aspects of this research were presented at the CHARISMA conference Leonardo da Vincis Technical Practice: Paintings, Drawings and Influence, The National Gallery, London, 13-14 January 2012, co-organized by the Centre de Recherche et de Restauration des Musées de France (C2RMF) and the British Museum, London (Dianne Dwyer Modestini, Beth A. Price, Nica Gutman Rieppi, Ken Sutherland, Robert Simon and Thomas J. Tague Jr., 'Leonardo da Vinci's 'Salvator Mundi' Rediscovered'); and at a symposium cohosted by New York University and Columbia University, February 18, 2012 (Nica Gutman Rieppi, Beth A. Price, Ken Sutherland, Thomas J. Tague Jr., "Leonardo da Vinci - Recent Technical Findings and Discoveries").
}

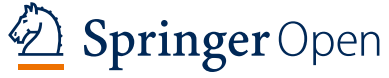

(c) The Author(s) 2020, corrected publication 2020. This article is licensed under a Creative Commons Attribution 40 International License which permits use, sharing, adaptation, distribution and reproduction in any medium or format, as long as you give appropriate credit to the original author(s) and the source, provide a link to the Creative Commons licence, and indicate if changes were made. The images or other third party material in this article are included in the article's Creative Commons licence, unless indicated otherwise in a credit line to the material. If material is not included in the article's Creative Commons licence and your intended use is not permitted by statutory regulation or exceeds the permitted use, you will need to obtain permission directly from the copyright holder. To view a copy of this licence, visit http://creativecommons.org/licenses/by/4.0/. The Creative Commons Public Domain Dedication waiver (http://creativeco mmons.org/publicdomain/zero/1.0/) applies to the data made available in this article, unless otherwise stated in a credit line to the data. 


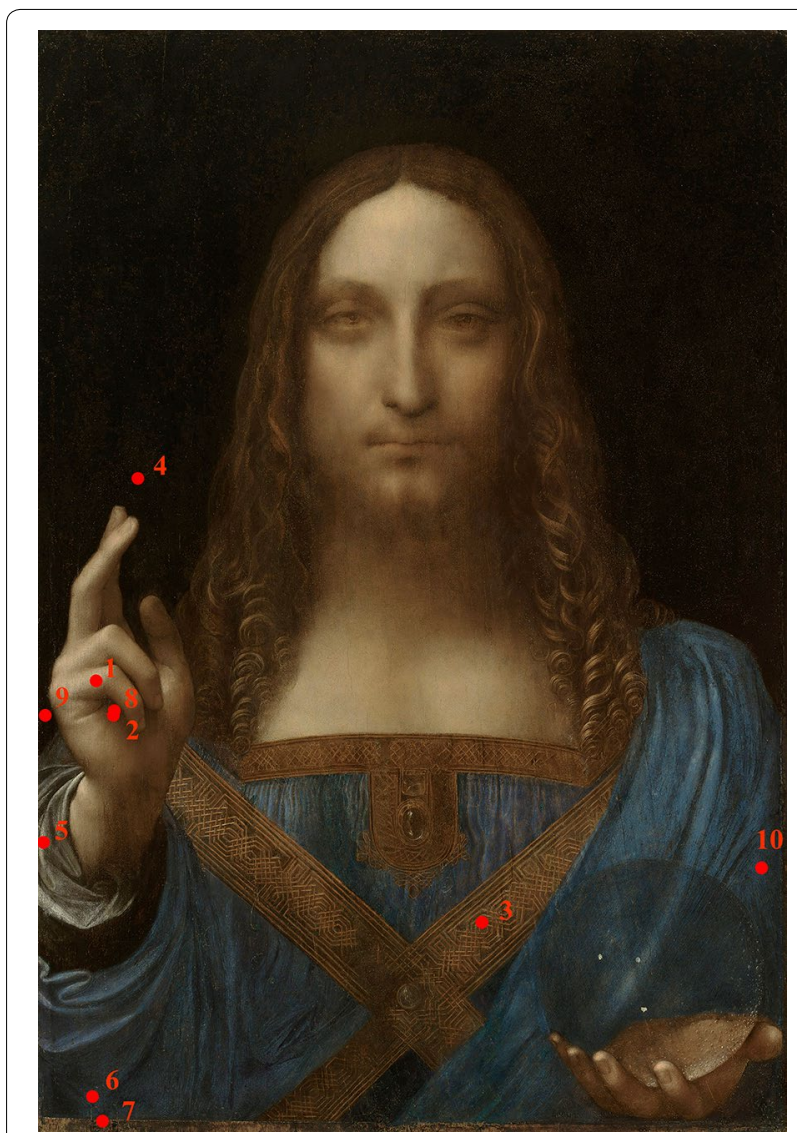

Fig. 1 Salvator Mundi, oil on walnut panel, c. 1500, with approximate sample locations marked (see also Table 1)

prepared as cross-sections to examine the layering structure and subsequent, non-original retouching. In 2011, in preparation for the exhibition 'Leonardo da Vinci: Painter at the Court of Milan' at the National Gallery, London, the cross-section studies were resumed and expanded to investigate the material composition of the paint layers. Analyses were undertaken using a complement of instrumental techniques: visible and fluorescent light microscopy (VLM and FLM), scanning electron microscopy with energy dispersive spectroscopy (SEM-EDS), Raman microspectroscopy, Fourier transform infrared microspectroscopy (MFTIR), FTIR with attenuated total reflection (ATR-FTIR), and pyrolysis gas chromatography-mass spectrometry (Py-GCMS). The scientific details of these results have not been published previously by the authors; in addition to shedding light on the artist's materials and techniques, they provide a basis for future technical studies of the Salvator Mundi.

\section{Methods}

\section{Stereomicroscopy and paint sampling}

The paint surface was examined in detail using stereomicroscopy (up to $50 \times$ magnification), informed by information derived from infrared reflectography [2]. Working under the stereomicroscope, ten microscopic samples that appeared to contain original paint layer structures were acquired using a surgical scalpel from locations adjacent to losses. The sampling locations were chosen to represent a range of colors and compositional elements. Instrumental analyses were carried out on nine of the samples prepared as cross-sections and on one unmounted sample for supplemental pigment and medium analysis. Sample details are listed in Table 1.

\section{Visible and fluorescent light microscopy (VLM and FLM)}

Samples for cross-sections were embedded in Bio-Plastic ${ }^{\circledR}$ polyester-polystyrene resin (Ward's Natural Science), cured, and polished with 4000 to 12,000 grade MicroMesh abrasives. The cross-sections were viewed in visible

\section{Table 1 Sample details}

\begin{tabular}{llll}
\hline Sample Number & Description & Location $^{\text {a }}$ & Sample Form \\
\hline 1 & Flesh highlight, proper right hand $[1,2,3]$ & $37 / 295$ & Cross-section \\
2 & Flesh shadow, proper right hand $[1,2,3,5]$ & $48 / 260$ & Cross-section \\
3 & Proper left diagonal band, area with underpainted knotwork design $[1,2,3]$ & $266 / 129$ & Cross-section \\
4 & Background (with overpaint) $[1,2,3]$ & $56 / 377$ & Cross-section \\
5 & Highlight of white cuff of sleeve, proper right hand [1, 2, 3] & $3.5 / 184$ & Cross-section \\
6 & Blue robe [1, 2, 3] & $49 / 16$ & Cross-section \\
7 & Blue robe, bottom edge [1, 2, 3] & $50 / 12$ & Cross-section \\
8 & Flesh shadow, proper right hand $[1,2,3,5]$ & $48 / 261$ & Cross-section \\
9 & Background (with overpaint), left edge [1, 2, 3] & $9 / 249$ & Cross-section \\
10 & Blue robe [1, 4, 6] & $406 / 154^{b}$ & Not embedded
\end{tabular}

Key: $1=$ VLM and FLM, $2=$ SEM-EDS, $3=$ Raman, $4=$ MFTIR, $5=$ ATR-FTIR, $6=$ PyGC-MS

a Sampling coordinates, distance from lower left corner $(\mathrm{x} / \mathrm{y}), \mathrm{mm}$

b Coordinates approximate since sample was taken while the painting was framed 
light and with ultraviolet-violet excitation, using a Leitz Laborlux S microscope, equipped with fiber optic lights for VLM and a Leitz D filter cube (355-425 nm excitation, $460 \mathrm{~nm}$ suppression filter) and $100 \mathrm{~W}$ mercury source for FLM. Samples were imaged using a Nikon Digital Sight DS-5M camera with Nikon EclipseNET software.

\section{Scanning electron microscopy with energy dispersive spectroscopy (SEM-EDS)}

Paint cross-sections were mounted on carbon tape on an aluminum stub; all were analyzed uncoated in low vacuum mode except sample 1 , which was carbon-coated using a Denton Desk II cold sputter coater with carbon rod evaporation accessory. Backscattered electron images and EDS spectra were acquired using a JEOL JSM-6460LV SEM equipped with an Oxford Instruments INCA X-sight EDS detector and INCA Energy 200 software. The accelerating voltage was $20 \mathrm{kV}$. The carbon coated cross-section was analyzed under high vacuum and the others at $30 \mathrm{~Pa}$. Supplementary, quantitative EDS analysis was undertaken on sample 1 in high vacuum mode, with an accelerating voltage of $20 \mathrm{kV}$ and a beam current of $\sim 1$ nanoamp. Corning Reference Glasses A, B, $\mathrm{C}$, and $\mathrm{D}$ were used as standards.

\section{Fourier transform infrared microspectroscopy (MFTIR and ATR-FTIR)}

Representative portions of sample 10 were isolated and flattened on a Spectra-Tech diamond window with a roller tool. Analyses were performed using a Thermo Nicolet Continuum microscope (MCT-A detector) attached to a Nexus 670 spectrometer. The data were collected in transmission mode between 4000 and $600 \mathrm{~cm}^{-1}$ at $4 \mathrm{~cm}^{-1}$ resolution and 200 scans per spectrum. Omnic 6.0 software was used for data treatment; spectra were processed using Happ-Genzel apodization. ATR-FTIR analyses were undertaken on cross-section samples 2 and 8. Data were collected using a Bruker Hyperion 3000 FTIR microscope, equipped with MCT detector and a $20 \times$ ATR objective with germanium (Ge) crystal. The microscope was attached to a Vertex 70 FTIR spectrometer equipped with a mid-IR Globar source. Data were collected from 4000 to $650 \mathrm{~cm}^{-1}$ at $4 \mathrm{~cm}^{-1}$ resolution, 512 scans per spectrum, using Blackman-Harris apodization and Mertz phase correction. Data were analyzed using Bruker OPUS software, version 6.5.

\section{Raman spectroscopy}

Cross-section samples were examined using a Bruker Senterra Raman microscope equipped with a $785 \mathrm{~nm}$ laser and 50x objective. Data were collected using $\sim 3 \mathrm{~cm}^{-1}$ resolution between 70 and $3500 \mathrm{~cm}^{-1}$ with a $20 \mathrm{~s}$ integration time and 2 accumulations per spectrum. The power on the samples was $\sim 1 \mathrm{~mW}$ to prevent transient heating. Area Raman images were collected using an Infinity 1 digital video camera and relevant spectra extracted from the video images. All data were processed using Bruker OPUS 6.5 software. Fluorescence and polarized light illumination facilitated sample observation and characterization.

\section{Pyrolysis gas chromatography mass spectrometry (Py-GCMS)}

A portion of the unmounted sample 10 (c. $10 \mu \mathrm{g}$ ) was placed in a Frontier Lab stainless steel sample cup, and $2 \mu \mathrm{L}$ of a $25 \%$ solution of tetramethylammonium hydroxide (TMAH) in methanol was added prior to insertion into a Frontier PY-2020iD vertical microfurnace pyrolyzer, attached to an Agilent 6890 N GC and interfaced to a $5973 \mathrm{~N} \mathrm{MS}$. The pyrolyzer furnace temperature was $550{ }^{\circ} \mathrm{C}$. The GC was equipped with J\&W DB5MS column (30 m, $0.25 \mathrm{~mm}$ i.d., $0.25 \mu \mathrm{m}$ film); oven temperature was programed from $40{ }^{\circ} \mathrm{C}$, with a 2 min hold, then increased at $20{ }^{\circ} \mathrm{C} / \mathrm{min}$ to $140{ }^{\circ} \mathrm{C}$, at $15^{\circ} \mathrm{C} / \mathrm{min}$ to $320{ }^{\circ} \mathrm{C}$, and held isothermally for $11 \mathrm{~min}$; total run time $30 \mathrm{~min}$. The inlet was operated with a split ratio of 1:10, with helium carrier gas at a flow rate of $1 \mathrm{~mL} /$ minute. The $\mathrm{MS}$ was run in scan mode $(\mathrm{m} / \mathrm{z} 35-600)$ with the source at $230{ }^{\circ} \mathrm{C}$ and quad at $150{ }^{\circ} \mathrm{C}$. Data were collected and processed using Agilent ChemStation software.

\section{Results and discussion}

The results of pigment analysis are summarized in Table 2 and are discussed below in the context of the painting's construction: that is, panel preparation and paint application; and in relation to its different compositional elements.

\section{Panel preparation}

The Salvator Mundi was executed on a walnut panel measuring $655 \mathrm{~mm}$ high by $451-456 \mathrm{~mm}$ wide [2]. The surface of the wood panel appears to have been prepared by sealing with an unpigmented size, observed as a discreet lowermost layer in several cross-sections (Fig. 2). Analysis by ATR-FTIR of this layer in sample 2 indicated a proteinaceous medium, likely animal glue, as suggested by $\mathrm{NH}$ stretch $\left(3295 \mathrm{~cm}^{-1}\right)$ and amide (1647 and $1533 \mathrm{~cm}^{-1}$ ) bands in the spectra.

Over the sizing (layer 1 in Fig. 2), a white ground layer was applied (layer 2), followed by a thinner, off-white priming or imprimitura ${ }^{2}$ (layer 3 ). The ground layer appears semi-translucent, with yellow discoloration

\footnotetext{
2 The term imprimitura is used in this paper to describe an overall, thin tinted preparation layer applied on top of the white ground.
} 
Table 2 Pigments characterized in the Salvator Mundi

\begin{tabular}{|c|c|c|c|}
\hline Color & Pigment & Ideal chemical-mineral name/formula & Occurrence \\
\hline \multirow[t]{3}{*}{ Red } & Vermilion $[2,3]$ & Mercuric sulfide/HgS & $\begin{array}{l}\text { Flesh highlights and shadows, warm brown } \\
\text { background underlayer, warm brown } \\
\text { underlayer of robe, warm gray under- } \\
\text { paint of diagonal band, lattice design of } \\
\text { diagonal band }\end{array}$ \\
\hline & $\begin{array}{l}\text { Possible red lake with alum-derived sub- } \\
\text { strate }[1,2]\end{array}$ & - & Blue robe, brown background underlayer \\
\hline & Iron oxide earth $[2,3]$ & Hematite, iron oxide $/ \mathrm{Fe}_{2} \mathrm{O}_{3}$ & Flesh shadows, lattice design, blue robe \\
\hline Yellow & Lead tin yellow type I [2] & Lead stannate/ $\mathrm{Pb}_{2} \mathrm{SnO}_{4}$ & $\begin{array}{l}\text { Imprimitura, lattice design, underpainted } \\
\text { knotwork of diagonal band, warm gray } \\
\text { underpaint of diagonal band }\end{array}$ \\
\hline Blue & Ultramarine, natural $[2,3,4]$ & $\begin{array}{l}\text { Lazurite/(Na, Ca })_{7-8}(\mathrm{Al}, \mathrm{Si})_{12}(\mathrm{O}, \mathrm{S})_{24}\left[\left(\mathrm{SO}_{4}\right)\right. \\
\left.\qquad \mathrm{Cl}_{2},(\mathrm{OH})_{2}\right]\end{array}$ & Blue robe \\
\hline Brown & Umber [2] & Iron oxide, manganese dioxide $/ \mathrm{Fe}_{2} \mathrm{O}_{3}, \mathrm{MnO}_{2}$ & Dark robe underpaint \\
\hline \multirow[t]{2}{*}{ Black } & Bone black [2] & $\begin{array}{l}\text { Carbon, calcium hydroxyapatite (mainly)/C, } \\
\mathrm{Ca}_{5}\left(\mathrm{PO}_{4}\right)_{3}(\mathrm{OH})\end{array}$ & $\begin{array}{l}\text { Initial black background layer, warm brown } \\
\text { background underpaint, warm brown } \\
\text { underpaint of robe and cuff, gray under- } \\
\text { paint of diagonal band, flesh shadows, } \\
\text { cuff of sleeve, background glaze layers }\end{array}$ \\
\hline & Carbon black [3], including charcoal [2] & Carbon/C & $\begin{array}{l}\text { Initial black background layer, warm brown } \\
\text { background underpaint, warm brown } \\
\text { underpaint of robe and cuff, dark robe } \\
\text { underpaint, warm gray underpaint of } \\
\text { diagonal band, flesh tones, cuff of sleeve, } \\
\text { background glaze layers; lattice design } \\
\text { (charcoal) }\end{array}$ \\
\hline White & Lead white $[2,3,4]$ & $\begin{array}{l}\text { Basic lead carbonate and lead } \\
\text { carbonate } / 2 \mathrm{PbCO}_{3} \cdot \mathrm{Pb}(\mathrm{OH})_{2} \text { and } \mathrm{PbCO}_{3}\end{array}$ & $\begin{array}{l}\text { Ground and imprimitura layers, flesh } \\
\text { highlights, cuff of sleeve, warm gray } \\
\text { underpaint of diagonal band }\end{array}$ \\
\hline \multirow[t]{2}{*}{ Transparent } & Soda lime glass $[2,4]$ & $(\mathrm{Na}, \mathrm{K})_{x}(\mathrm{Ca}, \mathrm{Mg}, \mathrm{Al})_{\mathrm{y}} \mathrm{SiO}_{2}$ & $\begin{array}{l}\text { Ground and imprimitura layers, initial } \\
\text { black background layer, warm brown } \\
\text { background underpaint, warm brown } \\
\text { underpaint of robe and cuff, blue robe, } \\
\text { flesh tones, cuff of sleeve }\end{array}$ \\
\hline & Quartz [2] & Silicon dioxide $/ \mathrm{SiO}_{2}$ & Blue robe, brown underlayer of robe \\
\hline
\end{tabular}

Key: 1 = FLM, 2 =SEM-EDS, $3=$ Raman, $4=$ MFTIR

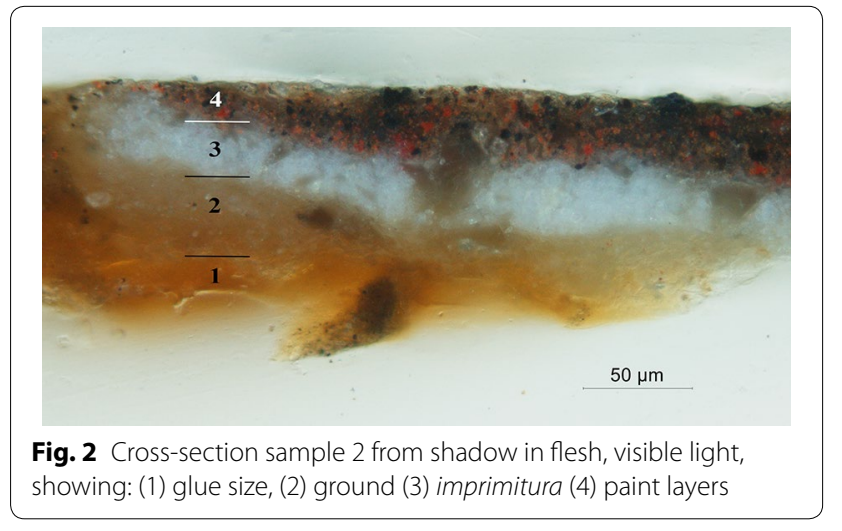

apparent along the lower interface adjacent to the underlying sizing material. Analysis of the ground and imprimitura revealed generally similar compositions, each containing a mixture of lead white pigment and lipid, likely oil, but with a small amount of lead-tin yellow pigment added to the imprimitura. The lead white pigment, comprising basic and neutral lead carbonates, was identified by combined EDS and MFTIR. Diagnostic IR spectral bands include a very strong carbonate stretch centered at $1406 \mathrm{~cm}^{-1}$ with weaker diagnostic bands at 1051, 839 and $678 \mathrm{~cm}^{-1}$ (neutral form) and 3538, 1045 and $682 \mathrm{~cm}^{-1}$ (basic form) [3]. Lead-tin yellow was indicated by the detection of lead $(\mathrm{Pb})$ and tin $(\mathrm{Sn})$ in yellow particles by EDS, with an absence of silicon ( $\mathrm{Si}$ ) implying the type I pigment. IR spectral bands suggesting a lipid/oil material were observed at 2927/2854, 1736 and $1170 \mathrm{~cm}^{-1}$. Imprimitura layers of similar composition-lead white with lead-tin yellow-have been found in Italian Renaissance paintings [4]. The presence of a lead white ground, rather than the more traditional calcium sulfate gesso ground, is less typical for this period. 


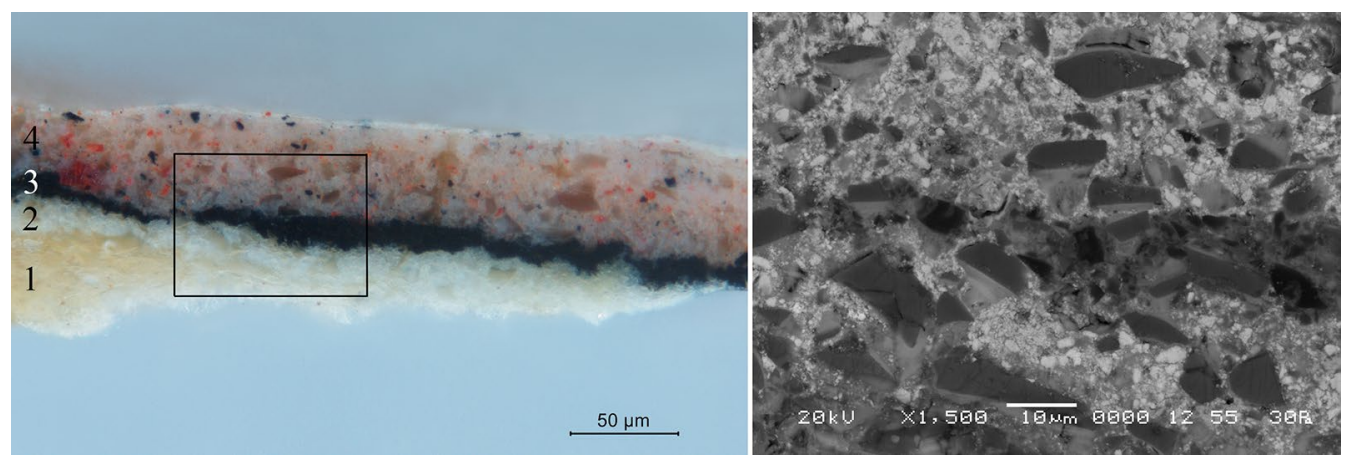

Fig. 3 Cross-section sample 1 from flesh highlight, proper right hand (left), showing: (1) ground (2) imprimitura (3) black background paint layer (4) flesh highlight paint layers; backscattered electron (SEM-BSE) image (right) corresponding to area with overlaid box, showing coarse glass particles in the lead white matrix of the ground and imprimitura, as well as the upper paint layers (3-4)

However, several paintings from the late fifteenth and early sixteenth century with panels prepared with lead white grounds laid directly over wood have been reported: at the Musée du Louvre, the Portrait of Bernardino di Salla (c. 1504-1509) by Giovanni Francesco Carota [5], and at the National Gallery, London, works including the Portrait of a Man Aged 20 ("The Archinto Portrait"), dated 1494, by Marco d'Oggiono and The Virgin and Child (c. 1500) by a Follower of Giovanni Antonio Boltraffio [6]. As with the Salvator Mundi, these paintings were constructed with panels made of walnut, a dense wood that would have been well-suited to accommodate an oil-based preparatory layer.

In addition to lead white pigment, the ground and imprimitura layers contain angular-shaped, colorless glass particles of variable size from less than one and up to 30 micrometers dimensions, and of a composition consistent with manganese-containing soda-lime glass, which has been reported elsewhere in Italian Renaissance paintings [7-11] (Fig. 3). FTIR spectra of the Salvator Mundi's glass particles exhibit a strong, broad $\mathrm{Si}-\mathrm{O}$ stretch centered at $1072 \mathrm{~cm}^{-1}$. The particles contain a large proportion of silicon with lesser quantities of sodium $(\mathrm{Na})$, magnesium $(\mathrm{Mg})$, aluminum $(\mathrm{Al})$, chlorine $(\mathrm{Cl})$, potassium $(\mathrm{K})$, calcium $(\mathrm{Ca})$, manganese $(\mathrm{Mn})$, and iron ( $\mathrm{Fe})$ as detected by qualitative EDS. Quantitative EDS analysis indicated the following composition for the glass (expressed as weight percent of oxides, excluding $\mathrm{Cl}$, which is given as elemental weight percent): $\mathrm{Na}_{2} \mathrm{O}$ (10.1), $\mathrm{MgO}$ (3.1), $\mathrm{Al}_{2} \mathrm{O}_{3}$ (2.5), $\mathrm{SiO}_{2}$ (65.0), $\mathrm{Cl}$ (0.7), $\mathrm{K}_{2} \mathrm{O}$ (5.2), $\mathrm{CaO}$ (9.1), $\mathrm{MnO}$ (3.2), and $\mathrm{FeO}$ (1.0). The observed $\mathrm{Na}: \mathrm{Ca}: \mathrm{K}$ ratios fit well with examples of soda-lime glass commonly encountered in Italian paintings, rather than the potash glass more typical for Northern Europe [7]. A small quantity of lead also was detected, most likely deriving from the lead white pigment and fatty acid soaps (lead carboxylates) present throughout the paint matrix in cross-section; the soaps are formed from reaction of the lead white pigment with the oil medium. An IR spectral band attributable to the lead soaps was observed at $1523 \mathrm{~cm}^{-1}$. These soaps may contribute to the perceived translucency of the ground layer, an alteration phenomenon in paintings that has been discussed extensively elsewhere [12].

With regard to the distribution of the glass particles in the Salvator Mundi, the ground layer exhibits a higher concentration than the thinner imprimitura layer, which is mainly lead white-based. Glass also was used extensively in various paint layers (see sections below). The implementation of pulverized glass by artists has been well documented in European paintings dated to the fifteenth- and sixteenth-centuries, especially those from Italy $[7-11,13]$. In a survey undertaken by the National Gallery (London), large, coarsely-ground glass particles, as detected in the Salvator Mundi, were found more frequently in Italian rather than northern paintings [7]. Likewise, the implementation of glass as an additive in oil-bound imprimiture was observed only in the Italian paintings [7].

It has been postulated that glass was added to improve the drying properties of oil media, with the siccative properties of soda-lime glass attributed to the presence of manganese, an active drier. Glass may alternatively have been used for aesthetic effect by enhancing the translucency of the paint, but in the case of the Salvator Mundi, the glass in the lower ground and imprimitura layers more likely functioned as a siccative since these layers are not visible in the final painted image. It also is possible that the glass was added to adjust the handling and textural properties of the panel preparation materials.

\section{Background}

Cross-section analysis combined with stereomicroscopic examinations and IRR [2] provided information about 


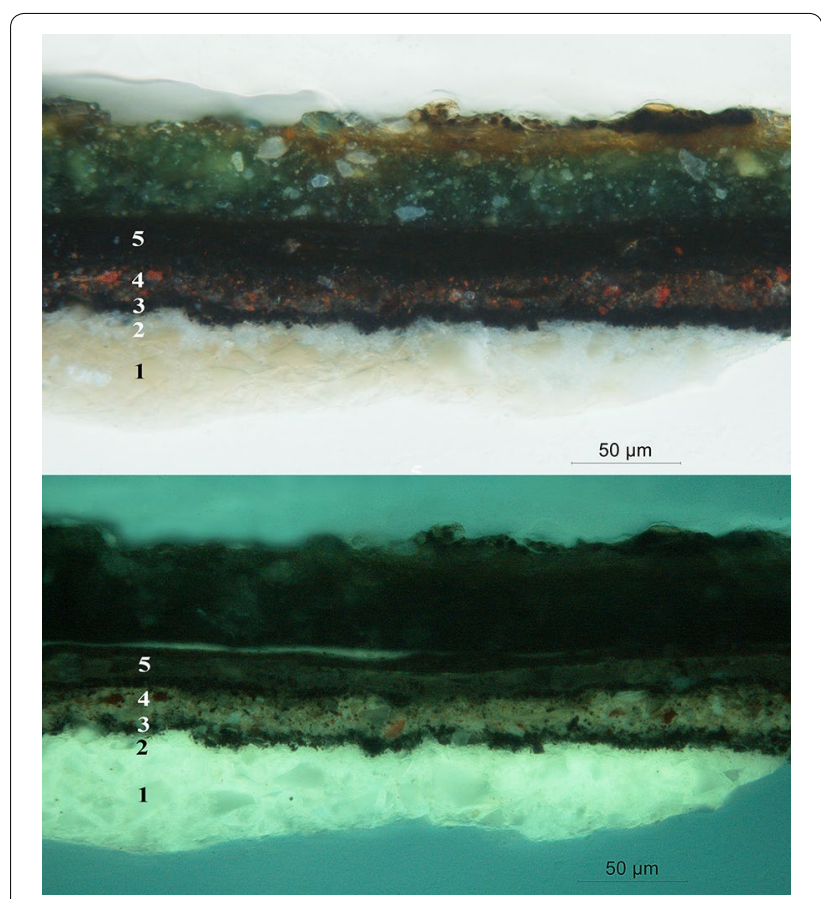

Fig. 4 Cross-section sample 4 from background, visible light (top) and ultraviolet fluorescence illumination (bottom), showing: (1) ground, (2) imprimitura, (3) initial black paint layer, (4) warm brown underpaint, (5) three black paint layers. Over these paint layers is a fluorescent, unpigmented layer and an uppermost green layer representing non-original overpaint; this aspect of the painting has been discussed in a separate publication detailing the restoration treatment [2]

the paint stratigraphy of the background of the composition. This part of the painting appears to have been executed with an initial, thin black paint application (the 'lay-in') that was applied directly over the imprimitura and subsequently built up with multiple warm-toned brown and black paint layers. The surviving remnants of the background paint, revealed after the cleaning of the painting, were uniformly dark and exhibited a similar warm black color, suggesting that the background may have been even in tone and hue overall [2].

This complex sequence of layers in the background can be seen in cross-section (Fig. 4). The initial thin layer of black paint (layer 3 in Figs. 3 and 4) visible above the imprimitura was found to contain finely ground carbon (C) and bone black (mainly $\mathrm{Ca}(\mathrm{PO})_{4}(\mathrm{OH})$ ) pigments in oil. The carbon black was identified from Raman spectra with peaks at 1580 and $1325 \mathrm{~cm}^{-1}$ [14]; bone black was indicated by the detection of calcium and phosphorous (P) by EDS. As with the ground and imprimitura layers, a generous amount of manganese-containing soda-lime glass was incorporated in the black paint. As discussed earlier, the glass may have served a drying function and to impart a translucent quality to the final paint surface and depth to the painted shadows.

The background was subsequently built up with multiple paint layers, the first of these warm brown in tone and comprising vermilion, carbon black, red lake, and glass particles (layer 4 in Fig. 4). Mercury (Hg) and sulfur (S) indicative of vermilion $(\mathrm{HgS})$ were detected by EDS, and Raman spectra showed characteristic bands for this pigment at 255 and $344 \mathrm{~cm}^{-1}$ [15]. The red lake pigment was not present in sufficient quantity in the cross-section to enable identification by methods available at the time of this study; however, the particles fluoresced orangepink under UV-violet illumination using FLM, and aluminum was detected by EDS, suggesting an alum-derived substrate. In the area sampled, several further paint layers, black in color, are situated above the warm brown layer (layers 5). These layers, ranging in thickness from approximately 3 to 5 micrometers, vary in pigment composition and translucency, containing variable combinations of carbon and bone black pigments, and may have served to further darken and attenuate the warmth of the background. With each successive paint application, the background would have become smoother with a greater depth and richness in tonality.

Regarding the initial black lay-in paint of the background, it appears from stereomicroscopic examination and IRR [2] to have been applied around the contour of the figure, leaving Christ's torso and head in reserve, that is, to be painted later. Interestingly, no reserve appears to have been made for the upper part of the raised hand with the blessing gesture, which was painted over the initial black lay-in paint of the background. This is illustrated in a cross-section corresponding to one of the fingers located above the figure's shoulder, in which the black lay-in layer is present on top of the imprimitura and beneath the subsequent flesh paint layers (Fig. 3). When examined with the stereomicroscope, the boundary of the black lay-in paint appeared to follow the contour of Christ's proper right shoulder, perhaps indicating that the raised hand was not included in the earliest conception of the image, or possibly representing the artist's oversight. This observation merits further investigation utilizing advanced imaging and mapping techniques.

\section{Christ's blue robe}

Analysis of two cross-sections from the Christ figure's blue robe, as well as a cross-section from the proper right white sleeve cuff, revealed a lowermost, semi-translucent warm brown paint layer (layer 2 in Figs. 5, 6), similar in appearance and composition to that described above in the background (containing vermilion and carbon black pigments mixed with glass particles), but in this case applied directly to the imprimitura layer rather 


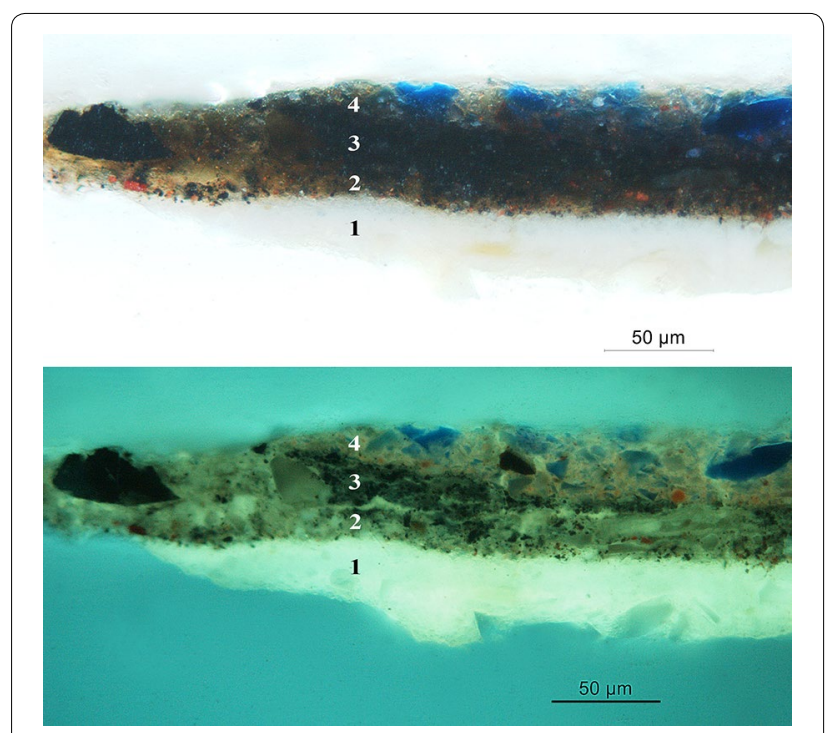

Fig. 5 Cross-section sample 6 from blue robe, visible light (top) and ultraviolet fluorescence illumination (bottom), showing: (1) imprimitura, (2) warm brown underlayer, (3) black or dark gray layer (4) blue paint

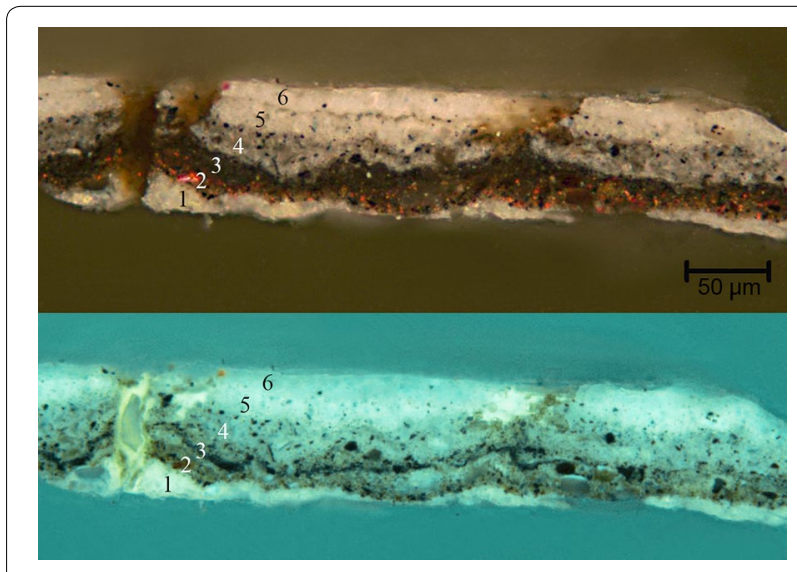

Fig. 6 Cross-section sample 5 from cuff of sleeve, proper right hand, visible light (top) and ultraviolet fluorescence illumination (bottom), showing: (1) imprimitura, (2) warm brown underlayer, (3) thin black or gray layer, (4) gray paint layer, (5) pale gray paint layer, (6) white paint layer

than on top of a black paint layer. The thickness of this warm brown layer varies in the cross-sections, suggesting that it may have been applied unevenly or in localized applications rather than as an overall even lay-in for the robe. The presence of similar brown underpaint in different compositional elements of the Salvator Mundi-the background and robe-suggest that it may have played a visual role, contributing to the overall warm tone of the final painted image. However, its effect on the overall appearance of the painting may be exaggerated by the painting's abraded condition [2]. The warm underpaint appears to have been applied selectively to areas of the robe and background, and is not present in samples taken from the flesh and the diagonal band of the stole.

The warm brown underpaint of the robe appears to have provided a mid-tone base upon which the subsequent paint layers of Christ's robe were built. In the cross-section (sample 6), a dark layer containing carbon black pigment can be seen superimposed on the warm brown paint (layer 3 in Fig. 5). This layer, which is not continuous across the sample, varies in thickness and appears medium-rich, suggesting that it may have been semi-translucent. Although the function of this black paint in relation to the robe overall is unclear, its apparent application prior to the final blue paint suggests that it may have served a modelling function, helping to establish light and shade.

The use of washes of monochrome modelling, rendered on top of preparatory layers prior to the application of the full range of color, is a technique employed in fifteenth and sixteenth century Italy. It may have gained influence through Andrea del Verrocchio's workshop, and has been identified in Verrocchio's The Virgin and Child with Two Angels (1467-1469), at the National Gallery, London [16]. Further examples, employing thin applications of brown and/or black paint, include the National Gallery's The Virgin and Child (1493-1499) by Giovanni Antonio Boltraffio and Salome (c. 1510-1530) by Giovanni Pietro Rizzoli (called Giampietrino), as well as the Galeria Nationale di Parma's La Scapiliata (c. 1500-1505) attributed to Leonardo da Vinci [17]. The prevalence of monochrome underpaintings of this type is unclear since they are most evident in rare, unfinished areas of paintings, of which known examples include Giovanni Antonio Boltraffio's Esterházy Madonna (c. 1495-1497) in the Szépmüvészeti Múzeum, Budapest [18, 19] and Leonardo's unfinished works such as the Gallerie degli Uffizi's Adoration of the Magi (c. 1482) [20].

The execution of the drapery of Christ's robe and manthe in the Salvator Mundi was continued with subsequent application of blue paint, containing natural ultramarine mixed with red lake and a small amount of a red iron oxide earth pigment, possibly added to enhance the warm tone of the blue (Fig. 5). Analysis of the blue pigment identified lazurite, a mineral component of lapis lazuli. A Raman spectral band was observed at $543 \mathrm{~cm}^{-1}$ [21] and IR bands at 1004 (1114 shoulder) and $2340 \mathrm{~cm}^{-1}$. This imported pigment was considered precious, its laborious preparation from the mineral source contributing to its cost [22]. No copper $(\mathrm{Cu})$ was detected in the crosssections by EDS to suggest azurite $\left[\mathrm{Cu}_{3}\left(\mathrm{CO}_{3}\right)_{2}(\mathrm{OH})_{2}\right]$ nor was azurite detected by MFTIR. The iron oxide pigment was suggested by the detection of iron using EDS and 
confirmed by Raman, with spectral bands for hematite located at 225 and $293 \mathrm{~cm}^{-1}$ [23].

Due to the worn and blanched condition of the blue paint of the robe, resulting from harsh past cleaning, along with sampling limitations, a detailed comparison of the highlights, midtones and shadows was not possible [2]. Furthermore, the blue has likely altered in tone, since ultramarine paints are prone to discoloration and red lake often fades over time [24-27]. However, the original blue probably was not brilliant and may have had a somewhat muted appearance resulting from the underlying dark paint and the poor covering power of ultramarine pigment, which can be somewhat translucent when used in oil without an added opaque pigment, such as lead white. In the Salvator Mundi, the use of an oil-based medium was determined by combined MFTIR and PyGCMS analysis of sample 10 taken from the blue robe, which gave results indicative of walnut oil: the fatty acid composition included a high level of azelaic acid and a ratio of palmitic to stearic acid of 2.7 [28]. The ratios of the dicarboxylic acids, which can sometimes provide evidence for heat bodying of drying oil, did not provide convincing information in this case (ratio of suberic:azelaic acid was 0.23 , a lower value than has been associated with heat bodied oils [29]). The single sample analyzed included the blue paint and semi-translucent black and warm brown underlayers, in addition to a small amount of the white preparatory layers; these layers could not be separated for individual analysis. Further sampling and analysis would be necessary to determine if walnut oil was used in other parts of the composition, or if additional oil types or different binding media were employed (Fig. 7).

\section{Bands of the stole and Christ's hair}

In some areas of the composition, microscopic surface examination along with cross-section analysis indicated an initial buildup using neutral shades of gray, or grisaille. Analysis of the cross-section from the proper left diagonal band in the drapery area (Fig. 8) reveals an initial application of light warm gray underpaint (layer 2) on top of the imprimitura, containing lead white, vermilion and carbon black pigments. Upon close examination of this area of the painting with a stereomicroscope, a monochromatic, asymmetrical knotwork design was observed below the upper paint surface (Fig. 9). The cross-section taken from an area where this underlying knotwork is present suggests that it was executed on top of the light warm gray underpaint using a pale yellow paint, containing lead-tin yellow pigment. This early knotwork design has a curvilinear, loosely interlacing pattern that does not match the final lattice design visible in the painting (Fig. 10). Alongside the pale yellow strokes of this

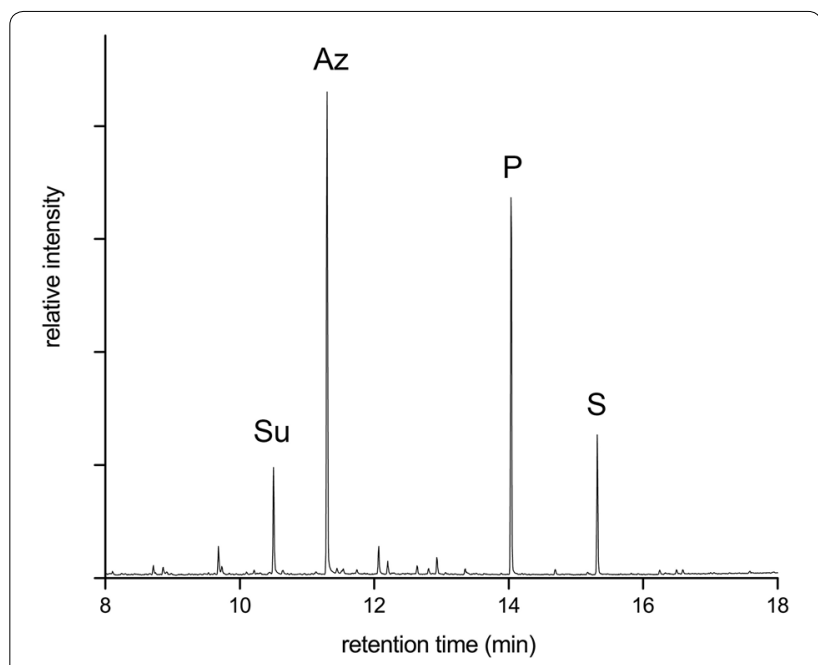

Fig. 7 PyGCMS data (total ion chromatogram) from analysis of paint sample 10; Su suberic, Az azelaic, $P$ palmitic, $S$ stearic fatty acid methyl ester derivatives

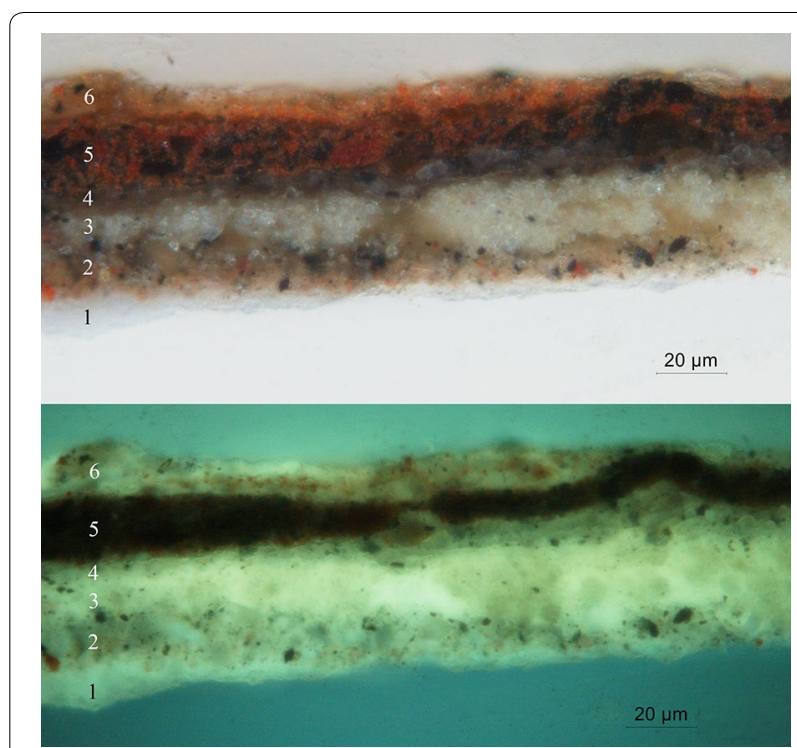

Fig. 8 Cross-section sample 3 from the proper left diagonal band of the stole, visible light (top) and ultraviolet fluorescence illumination (bottom), showing: (1) imprimitura, (2) warm gray paint, (3) yellow paint of knotwork design, (4) gray paint layer, (5) reddish brown paint layer, (6) orange-red paint layer

knotwork design, thin strokes of black or dark gray paint appear to have been loosely applied as cast shadows to create a relief against the underlying light warm gray paint. Stereomicroscopic examination and cross-section analysis show that the brownishred paint of the lattice design depicted in the final composition was applied on top of the underpainted knotwork design. Backscattered 


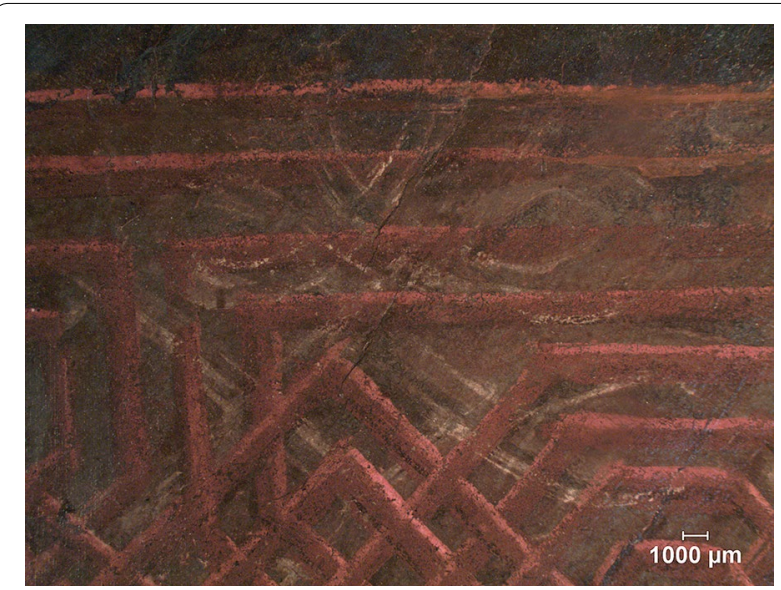

Fig. 9 Photomicrograph showing underpainted knotwork design present beneath the proper left diagonal band of the stole

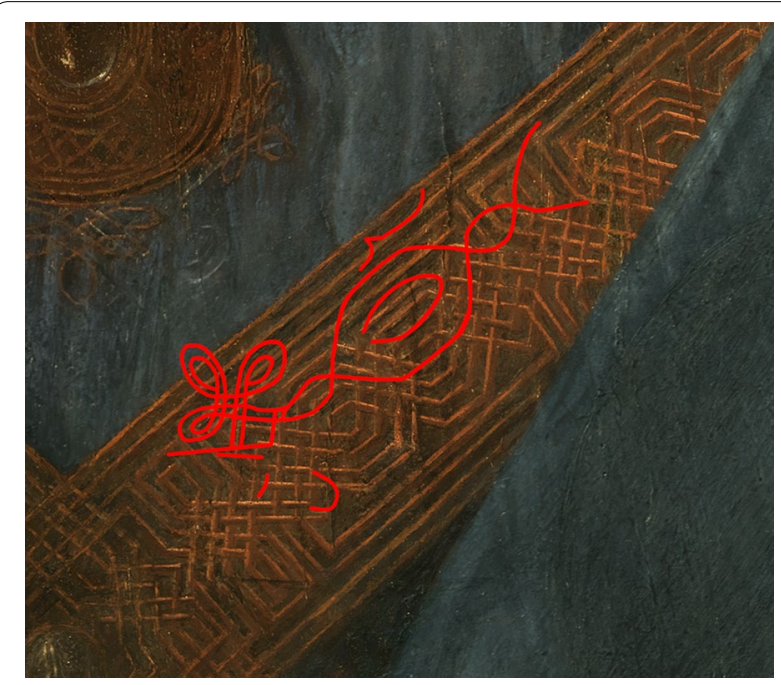

Fig. 10 Underpainted knotwork design seen beneath the painted lattice design of the proper left diagonal band of the stole, as observed through stereomicroscopic examination (mapped in red and superimposed over the corresponding area of the painting)

electron images revealed splintery particles in the vermilion-containing reddish-brown paint, which are characteristic of charcoal (Fig. 11). Cross-section analysis also reveals that the blue paint of the robe is not present in the layer structure of the sample taken from the proper left diagonal band: this, combined with stereomicroscopic examination, suggests that the bands were part of the conception of the image when the blue paint was applied.

In addition to the area of the proper left diagonal band, evidence was found for another underpainted decorative

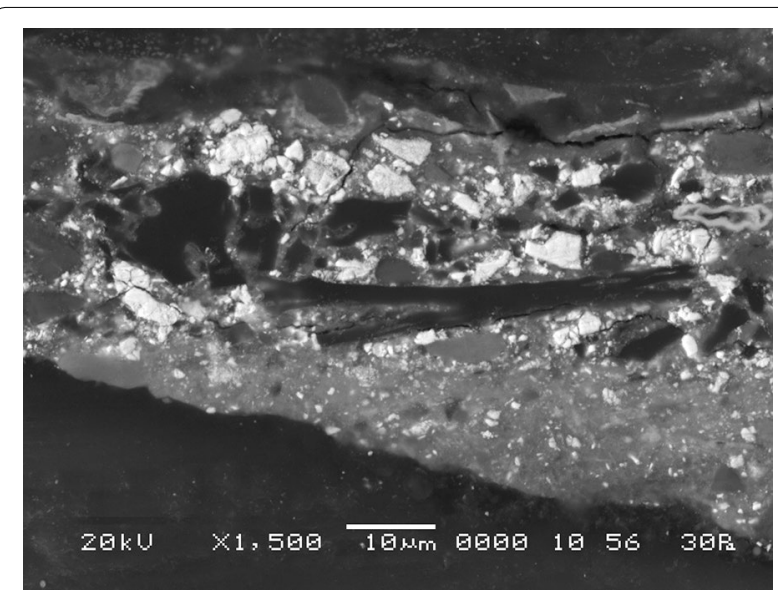

Fig. 11 Backscattered electron (SEM-BSE) image of paint of the lattice design of the proper left diagonal band of the stole, showing charcoal particles

design that appears to have been loosely painted for the central plaque, or pendant, on Christ's chest (not shown). Although it is only visible in certain areas, where upper lying blue paint had been abraded, it differs from the one seen in the final painted image. Further investigation utilizing advanced imaging and mapping techniques (not available at the time of the study) would be useful for elucidating these underpainted designs. While neither of these early designs appear to have been worked up in detail, they nevertheless provide testimony to creative process and give insight to the development of the composition.

Stereomicroscopic examination of areas of the horizontal breast band where upper paint layers were abraded also revealed grisaille underpainting in the form of an interwoven lattice pattern similar in design to that rendered in the visible composition (Fig. 12). Additional grisaille underpainting was observed in the lower tresses of Christ's hair, where the artist applied fine strokes of light gray paint before building up the color (Fig. 13).

\section{Flesh tones}

Cross-sections from the flesh paint suggest that the approach to establishing the flesh tones differed from that described for the drapery, for which monochromatic and grisaille underpaint appear to have been applied to establish the lights and shadows before the color was added. In the flesh, in contrast, a more brightly colored paint was applied first, on top of the imprimitura, upon which light and shade were established subsequently using multiple layers of paint. Surface examination and cross-section analysis suggest that the materials and approach for different types of flesh paint-highlights, 


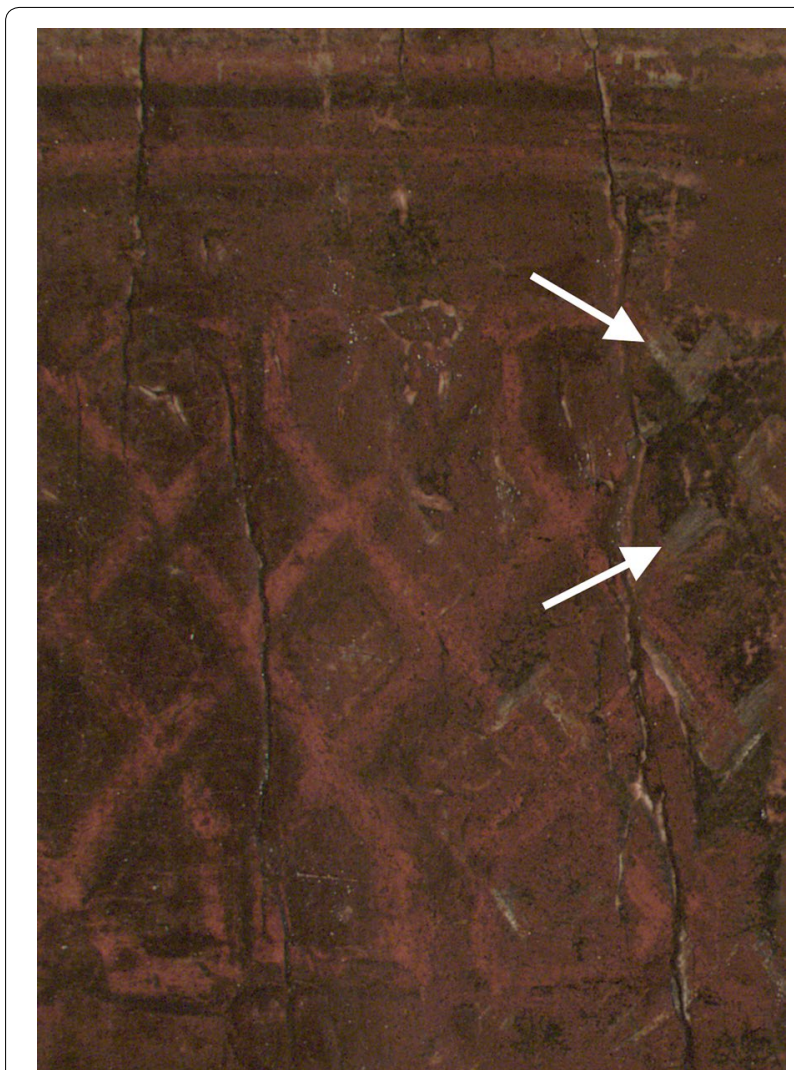

Fig. 12 Photomicrograph of lattice design of the horizontal breast band of Christ's robe, showing exposed area of grisaille underpainting (indicated by arrows)

shadows and mid-tones-varied. For example, in sample 1 taken from a bright highlight of the raised blessing hand, a base layer of saturated opaque pink, containing lead white, vermilion, glass particles, and a small amount of carbon black, was applied. The warmth of this layer was modified and attenuated with layers of slightly cooler and paler opaque paints, containing the same pigments but in differing proportions (Fig. 3). The highlights were finished with several extraordinarily thin (approximately 4-5 micrometers each) layers of cooler and paler pink paint to create the remarkably smooth surface of the final painted image (Fig. 14). No glass was detected in these uppermost, highlight paint layers.

In contrast to the highlights, the shadowed flesh of the raised hand appears to have been constructed with multiple layers of semi-translucent pigmented glazes. In cross-section 8, taken from the deep shadow of Christ's raised hand, the lowest brown-red layer is colored most intensely with vermilion and a small amount of carbon black. This layer is followed by multiple darker glaze layers, which appear to be more medium-rich, containing various mixtures of carbon and bone black particles with some vermilion. The glaze layers are thin, ranging in thickness from approximately 3 to 6 micrometers, and vary in degree of tone, warmth and translucency (Fig. 15). Red lake pigment appears to have been added to some of the layers, especially to the uppermost, thus imparting additional color and warmth. The subtle adjustments in the pigmentation of the glaze layers may have been used to create the modulations and enhance the depth and luminosity of the flesh shadows. The combinations of materials, layering techniques and paint manipulation described may account for the absence of visible brushstrokes, even under stereomicroscopic examination, with a physical smoothness of the paint surface that is most evident in Christ's face.

\section{Conclusions}

The scientific analysis of samples taken from the Salvator Mundi and stereomicroscopic examination of the painted surface have helped to provide an understanding of the material nature of the painting, as well as an insight into the techniques employed and paint handling effects achieved. The Salvator Mundi appears to have been executed using a fairly limited palette, including lead white, vermilion, red iron oxide earth, red lake, natural ultramarine, lead-tin yellow, umber, and charcoal, carbon and bone blacks. However, given the necessarily limited sampling performed, the presence of other pigments in the painting cannot be discounted. Further investigation utilizing advanced imaging and mapping techniques would be valuable to provide a more comprehensive overview of the pigments used and their distribution. Within each paint layer analyzed, the pigment mixtures are fairly simple, yet sophisticated visual effects were achieved by employing a complex sequence of layers.

Analysis provided insight to the stages of the painting's creation, with the walnut panel prepared with two lead white-containing layers bound in oil, the second of these tinted with lead-tin yellow. The overall tone of the Salvator Mundi may have been set partly through the use of warm brown underpaint, identified in areas of the background and robe, as well as with the lower more brightly hued warm underlayers of the flesh. The underlying dark and grisaille paint applications, as well as the earlier decorative designs of the stole, such as the underlying knotwork in the proper left diagonal band, provide insights to an artistic mind actively at work during the various stages of painting.

Examination of cross-sections showed some of the approaches that were used to render the painting's subtle visual effects. For the drapery, light and shade appear 


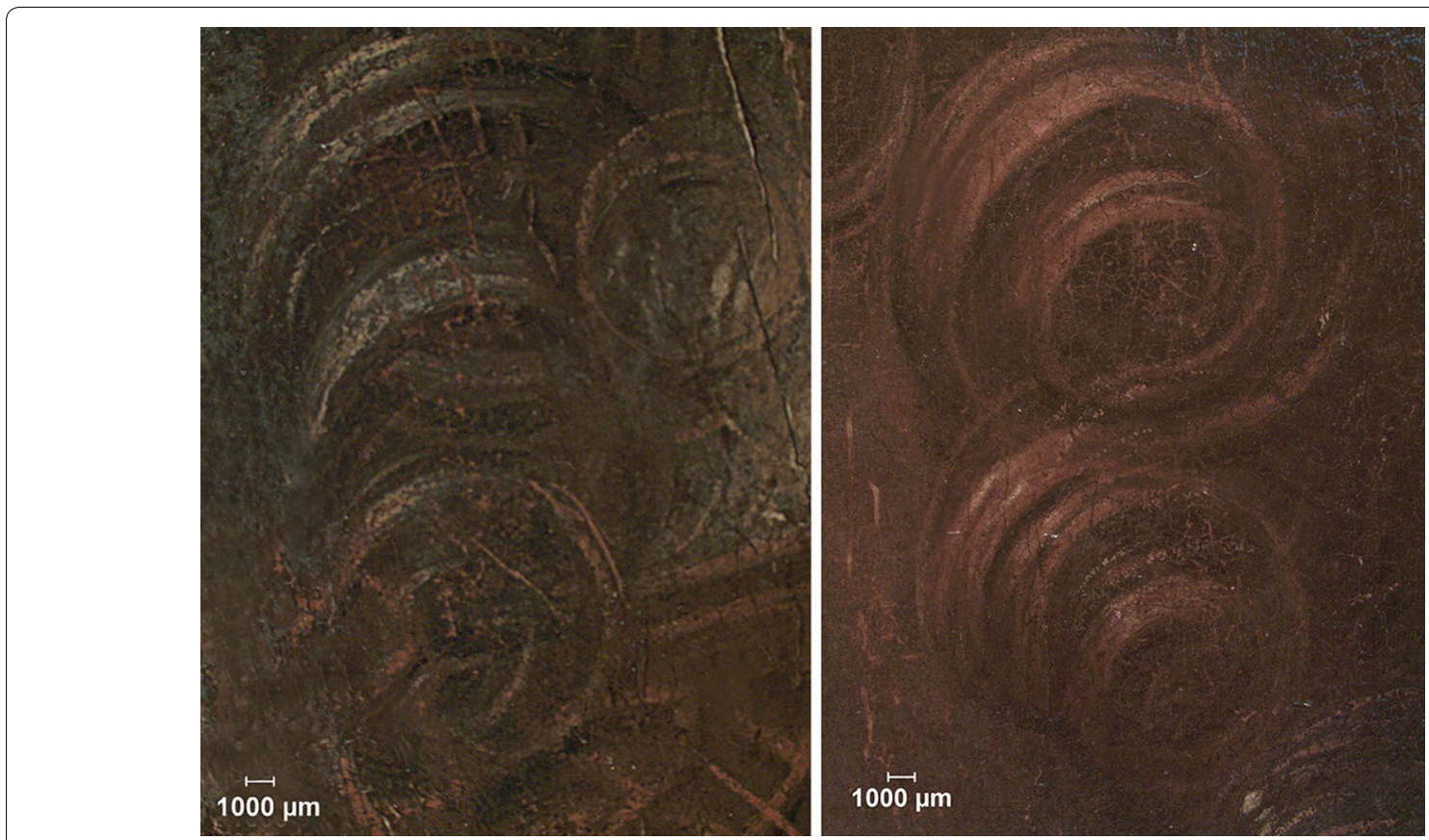

Fig. 13 Photomicrographs of curls of the lower tresses of Christ's hair, showing exposed grisaille underpainting (left) and a more intact painted curl (right)

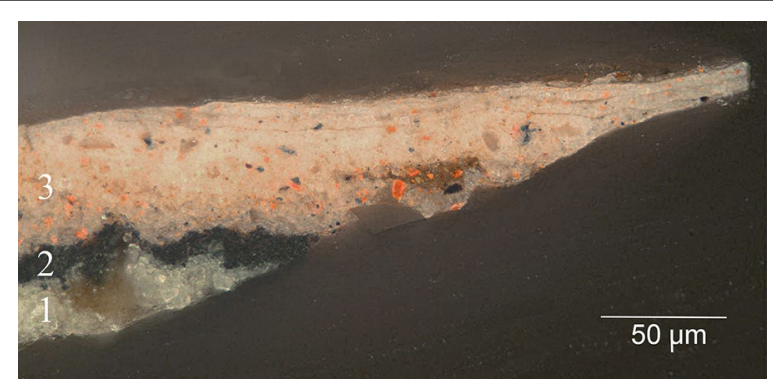

Fig. 14 Detail of cross-section sample 1 from flesh highlight, proper right hand, showing: (1) imprimitura (2) black background paint layer (3) flesh highlight paint layers. Several extraordinarily thin layers of cooler and paler pink paint, each approximately $4-5$ micrometers thick, are seen uppermost

to have been established in early stages through the use of dark, monochrome and/or grisaille underpaint applications, later enhanced by the layering of color. For the flesh, bright color appears to have been established first, its hue then attenuated by adding subsequent thin, intricate layers of light and/or shade. The combination of these approaches, and the addition of pulverized glass to the paint, helped achieved the luminosity, translucency and depth that characterize the Salvator Mundi.

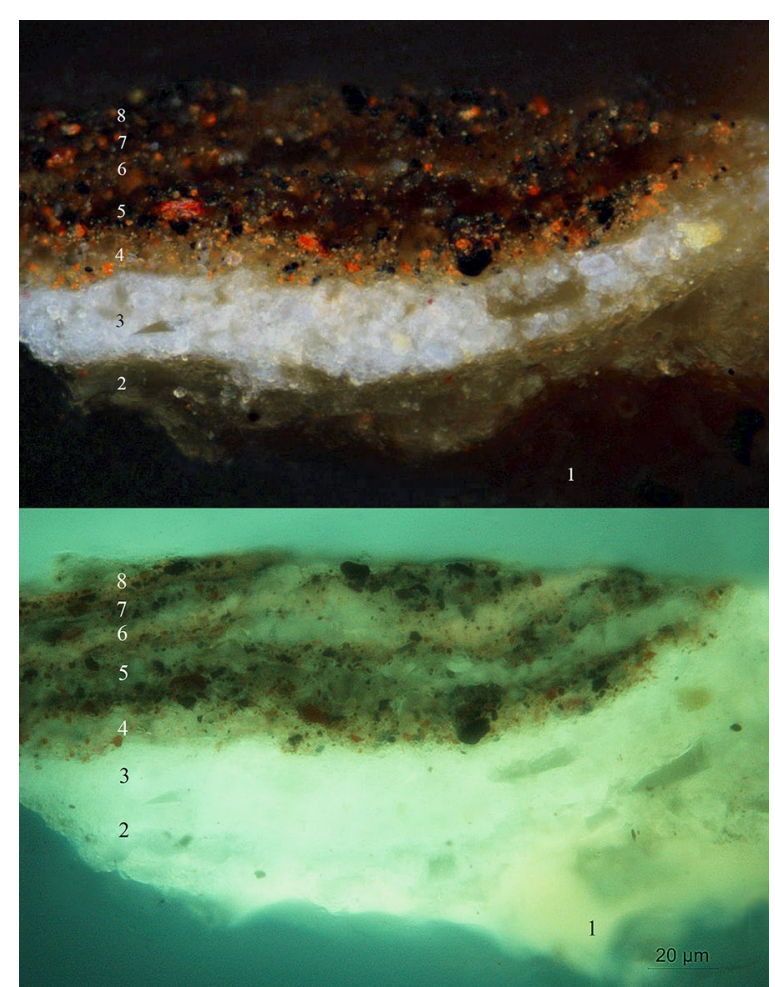

Fig. 15 Cross-section sample 8 from flesh shadows, visible light (top) and ultraviolet fluorescence illumination (bottom), showing: (1) glue size, (2) ground (3) imprimitura (4) brownish pink paint $(5,6,7,8)$ semi-translucent glaze layers 


\section{Abbreviations}

VLM and FLM: Visible and fluorescent light microscopy; SEM-EDS: Scanning electron microscopy with energy dispersive spectroscopy; MFTIR: Fourier transform infrared microspectroscopy; ATR-FTIR: FTIR with attenuated total reflection; Py-GCMS: Pyrolysis gas chromatography-mass spectrometry.

\section{Acknowledgements}

The authors would like to acknowledge conservator Dianne Dwyer Modestini, Clinical Professor, Kress Program in Paintings Conservation at the Conservation Center of the Institute of Fine Arts, New York University, for her guidance and expertise. This project would also not have been possible without the scholarship and expertise of Robert B. Simon, PhD. The type of wood used for the panel support was identified by George Bisacca, Emeritus Conservator of Paintings, The Metropolitan Museum of Art.

\section{Authors' contributions}

NGR performed stereomicroscopy, VLM and FLM, contextualization of data, and prepared the manuscript. BAP performed MFTIR and prepared the manuscript. KS performed SEM-EDS and Py-GCMS and prepared the manuscript. $P A L$ reviewed data and prepared the manuscript. RN performed quantitative EDS analysis of glass particles. PW and TW performed Raman microspectroscopy. TJT performed ATR-FTIR and Raman microspectroscopy. All authors read and approved the final manuscript.

\section{Funding}

Not applicable.

\section{Availability of data and materials}

All data generated or analysed during this study are included in this published article.

\section{Competing interests}

The authors declare that they have no competing interests.

\section{Author details}

${ }^{1}$ Art Analysis \& Research, LLC, New York, NY 10018, USA. ${ }^{2}$ Philadelphia, PA 19101, USA. ${ }^{3}$ The Art Institute of Chicago, 111 S. Michigan Ave, Chicago, IL 60603, USA. ${ }^{4}$ Museum of Fine Arts, 465 Huntington Avenue, Boston, MA 02115, USA. ${ }^{5}$ Bruker Optics Inc., 40 Manning Road, Billerica, MA 01821, USA.

Received: 30 November 2019 Accepted: 7 April 2020

Published online: 20 April 2020

\section{References}

1. Syson L. Leonardo Da Vinci: painter at the court of Milan. New Haven: Yale University Press; 2011.

2. Modestini DD. The Salvator Mundi rediscovered: History, technique and condition. In: Menu M, editor. Leonardo da Vinci's technical practice: paintings, drawings and influence. Paris: Hermann; 2014. p. 139-51.

3. Price BA, Pretzel B, Lomax SQ, editors. Infrared and Raman users group spectral database, vol. 1, 2, 2007 edn. Philadelphia: IRUG; 2009.

4. Dunkerton J, Spring M. The development of painting on coloured surfaces in sixteenth-century Italy. In: Roy A, Smith P, editors. Painting Techniques: History, Materials and Studio Practice, Contributions to the Dublin Congress, 7-11 September 1998. London: International Institute for Conservation of Historic and Artistic Works; 1998. p. 120-30.

5. Martin É. The preparation of the panel. In: Mohen J-P, Menu M, Mottin B, editors. Mona Lisa: inside the painting. New York: Abrams; 2006. p. 58.

6. Spring M, Mazzotta A, Roy A, Billinge R, Peggie D. Painting practice in Milan in the 1490s: the influence of Leonardo. Natl Gallery Tech Bull. 2011;32:78-112.

7. Spring M. Colourless powdered glass as an additive in fifteenth- and sixteenth-century European paintings. Natl Gallery Tech Bull. 2012;33:4-26.

8. Spring M. Perugino's painting materials: analysis and context within sixteenth-century easel painting. In: Brunetti GB, Seccaroni C, Sgamellotti A, editors. Postprints of the workshop on the painting technique of Pietro Vannucci, called il Perugino, organized by INSTM and LabSTECH, Perugia, 14-15 April 2003. Florence: Nardini; 2004. p. 17-24.
9. Roy A, Spring M, Plazzotta C. Raphael's early work in the National Gallery: paintings before Rome. Natl Gallery Tech Bull. 2004;25:4-35.

10. Berrie B, Matthew L. Material innovation and artistic invention: New materials and new colors in Renaissance Venetian paintings. Scientific Examination of Art: Modern Techniques in Conservation and Analysis. Washington DC: The National Academies Press, 2003. p. 12-26.

11. Tucker M, Passeri I, Sutherland K, Price B. Technique and Pontormo's Portrait of Alessandro de' Medici. In: Strehlke CB, editor. Pontormo, Bronzino, and the Medici: the transformation of the renaissance portrait in Florence. Philadelphia: Philadelphia Museum of Art; 2004. p. 34-54.

12. Noble P. A brief history of metal soaps in paintings from a conservation perspective. In: Casadio F, Keune K, Noble P, Van Loon A, Hendriks E, Centeno SA, Osmond G, editors. Metal soaps in art: conservation and research. Cham: Springer; 2019. p. 1-22.

13. Newman R. Observaciones acerca de los materiales pictóricos de Velázquez en Ciencia e Historia del Arte. In: McKim-Smith G, Newman R, editors. Velazquez en el Prado. Madrid: Museo del Prado; 1993. p. 113-47.

14. Coccato A, Jehlicka J, Moens L, Vandenabeele P. Raman spectroscopy for the investigation of carbon-based black pigments. J Raman Spectrosc. 2015;46:1003-15.

15. Bell IM, Clark RJH, Gibbs PJ. Raman spectroscopic library of natural and synthetic pigments (pre- $\approx 1850$ AD). Spectrochim Acta Part A Mol Biomol Spectrosc. 1997;53:2159-79.

16. Dunkerton J. Leonardo in Verrocchio's workshop: re-examining the technical evidence. Natl Gallery Tech Bull. 2011;32:4-31.

17. Keith L, Roy A. Giampietrino, Boltraffio, and the influence of Leonardo. Nat Gallery Tech Bull. 1996;17:4-19.

18. Chui SA, Phenix A. The Esterházy Madonna in the context of Leonardo da Vinci's studio practice. In: Menu M, editor. Leonardo da Vinci's technical practice: paintings, drawings and influence. Paris: Hermann; 2014. p. 169-81.

19. Chui SA, Phenix A. Giovanni Antonio Boltraffio's Madonna and Child in the context of Leonardo da Vinci's Milanese studio. Am Inst Conserv Hist Artistic Works Paint Spec Group Postprints. 2011;24:1-12.

20. Bambach C. Leonardo, Michelangelo and notions of the unfinished in art. In: Baum K, Bayer A, Wagstaff A, editors. Unfinished: thoughts left visible. New York: The Metropolitan Museum of Art; 2016. p. 30-41.

21. Bicchieri M, Nardone M, Russo PA, Sodo A, Corsi M, Cristoforetti G, Palleschi V, Salvetti A, Tognoni E. Characterization of azurite and lazurite based pigments by laser induced breakdown spectroscopy and microRaman spectroscopy. Spectrochim Acta Part B. 2001;56:915-22.

22. Cennini CA. The Craftsman's handbook "Il Libro dell'Arte". Transl. Thompson DV, Jr. New York: Dover Publication, Inc.; 1933. p. 36-9.

23. Burgio L, Clark RJ. Library of FT-Raman spectra of pigments, minerals, pigment media and varnishes, and supplement to existing library of Raman spectra of pigments with visible excitation. Spectrochim Acta Part A Mol Biomol Spectrosc. 2001;57:1491-521.

24. Bacci M, Cucci C, Del Federico E, lenco A, Jerschow A, Newman JM, Picollo M. An integrated spectroscopic approach for the identification of what distinguishes Afghan lapis lazuli from others. Vib Spectrosc. 2009:49:80-3.

25. Del Federico E, Schoefberger W, Schelvis J, Kapetanaki S, Tyne L, Jerschow A. Insight into framework destruction in ultramarine pigments. Inorg Chem. 2006;45:1270-6.

26. Del Federico E, Newman J, Tyne L, O'Hern C, Isolani L, Jerschow A. Solidstate NMR studies of ultramarine pigments discoloration. Mater Res Soc Symp Proc. 2007;984:45-50.

27. Saunders D, Kirby J. Light-induced colour changes in red and yellow lake pigments. Natl Gallery Tech Bull. 1994;15:79-97.

28. Mills JS, White R. The organic chemistry of museum objects. 2nd ed. Oxford: Butterworth-Heinemann; 1999. p. 171-2.

29. Mills JS, White R. Analyses of paint media. Natl Gallery Tech Bull. 1983;7:65-7.

\section{Publisher's Note}

Springer Nature remains neutral with regard to jurisdictional claims in published maps and institutional affiliations. 